\title{
AUtONOMIA EM TEMPOS DE CAPITALISMO FLEXÍVEL: UMA ABORDAGEM A PARTIR DE PAULO FreIRE
}

\author{
ANDERSON José LISBOA BAPTISTA \\ Universidade Federal Fluminense (UFF), Niterói, Rio de Janeiro, \\ Brasil
}

Resumo: O artigo reflete sobre a categoria de autonomia em Paulo Freire, sua relevância e aplicabilidade no atual estágio da sociedade capitalista. É uma abordagem teórica que, no primeiro momento, discute o conceito de corrosão do caráter (SENNET, 2014), no contexto do capitalismo flexível. Em seguida, apresenta a concepção de autonomia em Freire (2008, 2014a e 2014b), fundamentada em outros postulados de sua teoria. No final, são apontados contrapontos entre a lógica da sociedade do capitalismo flexível, da corrosão do caráter e a concepção freireana de autonomia. Entre os resultados, destaca-se a autonomia em Freire como uma proposta humanizante, que resgata o sentido de autoria e se contrapõe ao processo desumano que rege a sociedade capitalista atual.

Palavras-Chave: Autonomia. Autoria. Corrosão do Caráter. Inacabamento.

INTRODUÇÃO

Poucos discordariam da afirmativa de que a educação é elemento fundamental para uma sociedade melhor. Entretanto, esse aparente consenso começa a ruir à medida que aprofundamos a reflexão e questionamos o modelo de educação a que nos referimos e, principalmente, o que 
consideramos ser uma sociedade melhor. Longe de ser unanimidade, Paulo Freire é um dos autores brasileiros mais lidos no mundo e, provavelmente, o mais citado no Brasil quando o tema é educação. Isso tanto por aqueles que subscrevem a sua teoria quanto pelos que a combatem veementemente. Sua obra reflete sobre um modelo específico de educação e a construção de uma sociedade mais justa, por isso desconstrói criticamente alguns falsos consensos.

Partimos aqui da premissa da atualidade e da relevância do seu postulado teórico. Há uma persistência tanto no modelo de sociedade quanto no discurso hegemônico que ele combateu. Um exemplo está na insistente tentativa de propagar a concepção de uma educação neutra. Freire (2014b, p.201) chamou de "discurso velho" aquele que, em nome da neutralidade, exalta uma formação estritamente voltada ao treinamento técnico para o mercado de trabalho e suas condições. Enganam-se aqueles que pensam que velho seja sinônimo de ultrapassado. Pelo contrário, tal discurso permanece atual, uma vez que continua perfeitamente $a$ atender aos interesses daqueles que o proclamam.

Reconhecer a permanência no poder de determinados grupos hegemônicos que se articulam e se reinventam permanentemente para manterem não só o discurso, mas a configuração social que lhes é propícia, não significa, de forma alguma, negar as especificidades de momentos históricos.

Considerando tais perspectivas, este texto propõe uma reflexão sobre a categoria de autonomia em Paulo Freire e a sua relevância e aplicabilidade no atual estágio da sociedade capitalista, que, dentre outras características, pode ser reconhecida pelo que Sennet (2014) chama de corrosão do caráter.

Em tempos de profundas crises das instituições, nas quais o individualismo e a competitividade mercadológica ganham centralidade jamais vista na história da humanidade, perguntamos: em que sentido podemos relacionar uma prática educativa progressista à categoria de autonomia? Esta é uma desconfiança fundamentada, uma vez que tal categoria, conforme destaca a professora Edna Castro de Oliveira, no prefácio da obra Pedagogia da autonomia (Freire, 2008. p.11), foi incorporada ao ideário neoliberal com uma inversão, cujo objetivo é "estimular o individualismo e a competitividade".

O presente texto está dividido em três partes. No primeiro momento, após uma breve contextualização histórica, apresentamos o conceito de corrosão do caráter (SENNET, 2014) e suas principais características na sociedade contemporânea. Em seguida, discutimos o conceito de autonomia em Paulo Freire, fundamentados em outros aspectos da sua própria teoria. 
Encerramos com alguns contrapontos à lógica da corrosão do caráter a partir da categoria de autonomia em Paulo Freire, provando a atualidade e a relevância dessa concepção.

\section{SOCIEDADE DO CAPITALISMO FLEXÍVEL}

Hobsbawm (2008, p.391,393) denomina as décadas que sucederam ao ano de 1973 como"o desmoronamento". E, mais, refere-se aos 20 anos pós1973 como a história de "um mundo que perdeu suas referências". Afinal, que referências eram essas? Trata-se, em grande parte, de um modelo que teve seu clímax no período em que esse mesmo autor chamou de "era de ouro". Foi o momento áureo do Estado de bem-estar social, que se solidificou em parte do mundo capitalista, principalmente nos países ricos. Certamente, o contexto histórico posterior à Segunda Guerra Mundial foi propício ao modelo de bem-estar social que, de certa forma, oferecia algum tipo de segurança à população, principalmente das grandes potências europeias que foram devastadas pela guerra.

O período pós-Segunda Guerra caracterizou-se pela polarização do mundo entre as potências capitalistas e socialistas. O Estado de bemestar social era uma forma de proclamação do sucesso capitalista, que dava ao Estado o papel de garantidor de determinados bens sociais, como um sistema de previdência e assistência à saúde, por exemplo. A era de ouro expressou o momento de grande "êxito". Foi nesse período, na década de 1960 mais precisamente, que potências capitalistas chegaram a divulgar o pleno emprego (HOBSBAWM, 2008).

Contudo, essa realidade se solidificou apenas nas grandes potências. Em países periféricos, de capitalismo dependente como o Brasil, por exemplo, não tivemos um modelo liberal que garantisse de fato direitos sociais considerados essenciais, como saneamento básico, saúde, educação, etc. $\mathrm{E}$ até mesmo grandes potências capitalistas viviam no seu interior contradições inerentes a uma sociedade de classes. Mesmo porque a "era de ouro" foi sucedida por uma grande crise.

Na concepção de Hobsbawm (2008, p.283), esse foi o tempo de maior transformação social na história da humanidade. $O$ mundo passara por momentos importantes de mudança em outros períodos históricos, porém "a novidade dessa transformação está tanto em sua rapidez quanto em sua universalidade". O processo de urbanização alcançou velocidade e proporção jamais presenciadas, o que significou grandes mudanças na vida em sociedade. Os desenvolvimentos tecnológicos contribuíram com um vertiginoso aumento da produção e para a construção de uma sociedade pautada no consumo. 
Sem se furtar dos aspectos estruturais, Sennett (2006) propõe uma abordagem desse período baseada no conceito weberiano de burocracia. Para ele, o capitalismo social, termo que usa para descrever essa etapa, teve como característica principal uma organização burocrática que se assemelhava à militar, na qual os papéis e as funções profissionais/sociais eram bem demarcados e, por isso, havia espaço para a construção de narrativas de longo prazo.

Enfim, muitos são os elementos econômicos, sociais e culturais desse período que não cabem ser analisados neste texto. $O$ que nos interessa é pensarmos que tal momento do capitalismo, pautado em um modelo de segurança garantido pelo Estado de bem-estar social, entrou em colapso com a crise da década de 1970 e, consequentemente, essa crise gerou uma "nova" forma de organização do sistema capitalista e consequentemente um novo ethos social, que não foi capaz de resolver as contradições inerentes ao sistema capitalista, mas as acentuou. Ela serviu adequadamente para a consolidação do pensamento de grupos de intelectuais, como Hayek (1990) e Friedman (1988), entre outros, que defendiam uma exacerbação do individualismo e apostavam no mercado como principal regulador das relações políticas, econômicas e sociais. Foi o cenário ideal para a implementação de princípios ultraliberais que davam ao já poderoso mercado um poder praticamente ilimitado.

Esse período contou com uma reestruturação produtiva. A partir do toyotismo, a produção em massa foi substituída por um sistema produtivo pulverizado em vários países. O Estado de bem-estar social cedeu lugar ao neoliberalismo, que, ao contrário do modelo antecessor, propõe um Estado mínimo e sem compromisso com direitos sociais. O papel principal do Estado seria garantir o bom funcionamento do mercado sem interferir nele, a não ser para salvá-lo de colapsos, conforme presenciamos nas crises mais recentes.

O sistema de acumulação flexível, como também ficou conhecido, trouxe consigo importantes mudanças nas relações de trabalho e sociais. Significou nova forma de organização da desigualdade e se estruturou a partir de uma lógica distinta do modelo burocrático do capitalismo social.

Segundo Sennett (2006, p.20), essas novas propostas de ordenação produtiva e de mudança nos locais de trabalho atingiram, no primeiro momento, apenas grandes empresas de setores mais avançados da economia. Contudo, foram suficientes para influenciar a cultura e a organização social em geral, uma vez que são esses grupos que "indicam a nova formulação das capacidades e capacitações pessoais; a fórmula que reúne instituição e capacidade é que modela a cultura do consumo; os comportamentos em matéria de consumo, por sua vez, influenciam a política". 
A nova mentalidade econômico-empresarial trocou o poder gerencial pelo poder acionário e, consequentemente, passou a enfatizar resultados de curto prazo. $O$ interesse pelo controle de estoques acionários de longo prazo cede lugar à compra e à venda de dividendos em um mercado mais fluido. Um exemplo é que "enquanto em 1965 os fundos americanos de pensão retinham estoques em média durante 46 meses, em 2000 boa parte das carteiras desses investidores institucionais tinha rotatividade média de 3,8 meses" (SENETT, 2006, p. 43).

Há também uma reestruturação na arquitetura das instituições e nas relações de poder que se estabelecem com novas estratégias de controle que ocorrem a partir de um centro de comando direto. As novas tecnologias possibilitam que esse controle se dê a distância, uma vez que a pulverização geográfica de linhas de produção e de setores distintos é uma realidade desse modelo. A autoridade institucional é praticamente extinta, juntamente com as intermediações nas relações com os empregados, o que, para Sennett (2006), limita as possibilidades de interpretações individuais. A estabilidade institucional, outrora almejada, torna-se quase sinônimo de fraqueza. A virtude de uma organização passa a ser encontrada na sua flexibilidade e na sua capacidade de adaptação à volatilidade do mercado.

Dentro desse contexto, podemos compreender a tese de Sennett (2014, p. 11) sobre a corrosão do caráter:

O termo caráter concentra-se sobretudo no aspecto a longo prazo de nossa
experiência emocional. É expresso pela lealdade e o compromisso mútuo
pela busca de metas a longo prazo, ou pela prática de adiar a satisfação em
troca de um fim futuro. Da confusão de sentimentos que todos estamos
em algum momento particular, procuramos salvar e manter alguns; esses
sentimentos sustentáveis servirão a nossos caracteres. Caráter são os traços
pessoais a que damos valor em nós mesmos, e pelos quais buscamos que
os outros nos valorizem.

Dois aspectos são fundamentais nessa definição de caráter: o aspecto de longo prazo e a lealdade e a mutualidade dos compromissos. Porém, a sociedade do capitalismo flexível tem características que, de certo modo, nos afastam desses aspectos e, por isso, "corroem o caráter". Entre elas, podemos destacar: a impaciência e o imediatismo como consequência de uma economia dedicada ao curto prazo e à otimização dos lucros, independente de fatores humanos; e a fragilidade e a volatilidade das instituições e das relações sociais, como consequência de um modelo que exacerbou o individualismo e que abriu mão da lógica da coletividade em proveito do lucro e do sucesso pessoal e instantâneo (SENNETT, 2014). 
Diante de tais características, observamos em um plano mais direcionado por que Hobsbawm (2008) falava em um mundo que havia perdido suas referências. Este é o mundo do capitalismo flexível, que produz a corrosão do caráter e que, dentro desse contexto, propaga a necessidade de sujeitos autônomos e adaptáveis às suas vicissitudes, que na prática são configuradas ou ditadas pelo mercado. $\mathrm{O}$ que significa ou pode significar uma educação para a autonomia dentro de tal realidade?

Para responder a tal problemática, precisamos refletir ainda de modo mais específico sobre as vicissitudes que acompanham esse modelo que rege a sociedade nos dias de hoje.

Sennett (2014) faz uma análise sobre as novas formas de organização e até mesmo de relações no mundo do trabalho, oriundas do capitalismo flexível, e destaca o quanto elas se propagaram para outras dimensões da vida, tornando-se verdadeiras cosmovisões e, consequentemente, afetando diretamente a sociedade.

O modelo de organização flexível é marcado pela aleatoriedade, o que significa um rompimento com a ênfase sequencial oriunda do fordismo. Nesse tipo de organização, não há muito espaço para a previsibilidade, por isso o trabalhador precisa estar sempre pronto para possíveis mudanças. Isso faz como que a ansiedade e o estresse sejam marcas da sociedade contemporânea. Para Sennett (2006), há uma diferença entre ansiedade e medo. Este ocorre quando o indivíduo sabe o que vai acontecer, o que esperar. Aquela, porém, é consequência da imprevisibilidade da insegurança, baseada naquilo que poderá acontecer, por isso gera estresse.

A dimensão tempo nessa nova etapa do capitalismo é um dos fatores que refletem essa mudança social. Não se trata da velocidade na troca de informações, nas relações comerciais ou na execução de determinadas tarefas, mas sim na relação da humanidade com a categoria tempo. É aí que está a questão. A sociedade do capitalismo flexível tende a romper com tudo o que está relacionado a longo prazo. É a sociedade do imediatismo, das soluções rápidas, do fast-food.

Há um rompimento com as narrativas. Se partimos do princípio de que o caráter se relaciona ao que está voltado para o longo prazo, a flexibilidade do tempo atual cria uma tensão entre o caráter e a"experiência do tempo desconjuntado", o que acaba ameaçando "a capacidade de as pessoas transformarem seus caracteres em narrativas sustentadas" (SENNETT, 2014, p. 32).

Se não existe compromisso com um tempo a longo prazo, planejado, com a trajetória, com a carreira profissional, tem-se lugar para tempos 
desajustados e desorganizados, o que, para Sennett (2014, p.117), contribui para uma sociedade superficial."A seta do tempo se partiu; não tem trajetória numa economia política continuamente replanejada, que detesta a rotina, e de curto prazo."

Em outras palavras, as relações historicamente produzidas no contexto do capitalismo flexível modificaram o vínculo do homem com o tempo.

Isso afeta diferentes esferas da vida, inclusive a relação com o conhecimento e consequentemente com a educação. Quais as expectativas de sujeitos que vivem dentro dessa lógica em relação à educação e ao trabalho? É a busca de soluções imediatas para demandas específicas. Não é por acaso que o tempo de formação de muitos cursos está diminuindo consideravelmente.

Porém, o mesmo mercado voltado para uma formação mais superficial exige do trabalhador uma capacidade de rápida adaptação às mudanças. Apesar da limitação e da especificidade da formação aligeirada, o trabalhador deve estar sempre pronto para se adequar a elas.

Enganam-se aqueles que pensam que essa capacidade de adaptação está relacionada a um conhecimento profundo que se espera do trabalhador em relação aos fundamentos de determinada tecnologia ou ciência. Pelo contrário, dentro dessa lógica, as tecnologias tendem a substituir o ser humano em questões de maior complexidade, cabendo ao trabalhador o conhecimento que lhe dê a capacidade de executar tarefas. A figura do professor generalista é um exemplo clássico no campo da educação. Para que um professor especialista de História, se podemos passar o conteúdo através de um DVD? Neste caso, basta a figura de um "facilitador", que faça a intermediação entre os alunos e o que foi explicitado na aula.

O trabalhador considerado autônomo nesse contexto é aquele capaz de se adaptar às mudanças rapidamente e por conta própria.

Essa forma de lidar com o tempo, descompromissada com narrativas mais longas, com o longo prazo, afeta também as relações interpessoais. Como não há compromisso com o que é mais durável, as formas de associação passageira passam a ter mais sentido. Segundo Sennett (2014, p. 25), isso contribui para a formação de laços sociais fracos, que "se concretizam no trabalho de equipe, em que a equipe passa de tarefa em tarefa e muda de pessoal no caminho".

No âmbito dos laços humanos, as pessoas sentem falta de relações mais consistentes e com objetivos mais duráveis. A lógica de uma economia de curto prazo, que incentiva o consumo pelo consumo, influencia diretamente as relações humanas e sociais. 
A relação direta entre lógica do mercado e lógica da vida é propagada por um sistema que deu ao mercado e às relações econômicas uma centralidade em que o sentido de humanidade cede lugar ao princípio de mercadoria. A concepção de autonomia propagada pelo pensamento neoliberal converte-se às conveniências do mercado. $O$ que significa enquadrar o trabalhador na sua lógica.

A corrosão do caráter, à medida que rompe com a possibilidade de narrativas significativas, fere diretamente a possibilidade de autoria e consequentemente de autonomia, se partirmos da premissa de que esta "engloba tanto a liberdade de dar a si os próprios princípios quanto a capacidade de realizar os próprios projetos" (ZATTI, 2007, p. 11).

Friedman (1988) destaca que a liberdade individual é mediada pelo mercado. Por isso, quando o neoliberalismo cunha para si a categoria de autonomia, converte-a na possibilidade de o indivíduo tomar para si a capacidade de manter-se competitivo diante dos desafios do mercado. O que faz do sujeito o único responsável pelo seu sucesso ou fracasso, independentemente das condições materiais que o cercam. De certa forma, é o que fundamenta o discurso da meritocracia, que parte da premissa de que todos têm oportunidades e que o sucesso é impulsionado pela competitividade e depende das individualidades.

Isso ocorre ao mesmo tempo em que a lógica da corrosão do caráter tira do sujeito a possibilidade de um protagonismo real de sua história e o submerge em uma profunda crise de identidade e de referenciais. Em um país como o Brasil, a ausência de direitos sociais fundamentais intensifica essa lógica perversa. Daí surge a questão: é possível pensar em uma educação para a autonomia a partir do contexto supracitado? Quais marcos referenciais podemos usar para tal?

O pensamento de Paulo Freire sobre o tema é um importante caminho para refletirmos sobre tais proposições.

\section{Autonomia e educação em Paulo Freire}

A relação entre educação e autonomia remonta a tempos muito anteriores ao intelectual Paulo Freire. Não nos propomos aqui a fazer uma abordagem histórico- conceitual da palavra. Isso implicaria uma análise que ultrapassaria em muito os limites deste artigo. Mas não podemos desconsiderar algumas concepções sobre autonomia e sua relação com a educação pensadas na Modernidade e no lluminismo.

Em análise sobre o tema, Zatti (2007) destaca que Maquiavel combinou dois sentidos de autonomia relacionados à liberdade de 
dependência e ao poder de legislar. Já o reformador Martinho Lutero associou a autonomia como liberdade de dependência à liberdade espiritual. Os autores iluministas apresentam uma definição de autonomia que liberta o homem da superstição e da ignorância e que é voltada para a razão, que se fundamenta nas evidências empíricas e matemáticas. A razão seria o instrumento capaz de reduzir o sofrimento humano e, consequentemente, Ihe conferir autonomia.

Segundo Zatti (2007, p.17), é com o filósofo Immanuel Kant que o tema autonomia ganha mais força e centralidade, pois "ele faz uma transposição filosófica e crítica da autonomia religiosa de Lutero para autonomia moral. [...] Combina os dois sentidos usados por Maquiavel em uma explicação de determinação da vontade".

Em Kant $(2007$, p.85) autonomia é a capacidade de autodeterminação, relacionada à vontade que, para ele, é "independente da natureza dos objetos do querer". Sendo assim, a autonomia só ocorre de fato quando uma ação ou uma escolha não são motivadas por fatores externos.

É por meio da educação que o ser humano pode racionalmente desenvolver tal capacidade. Na obra Sobre a pedagogia, ele destaca que uma educação formadora de sujeitos autônomos tem a disciplina como a parte negativa, por ser aquela que impede os defeitos, e a instrução como parte positiva. A educação lida ao mesmo tempo com a submissão ao constrangimento das leis e com o exercício da liberdade. Para que o homem experimente a liberdade de fato, é preciso que "sinta logo a inevitável resistência da sociedade, para que aprenda a conhecer o quanto é difícil bastar-se a si mesmo, tolerar as privações e adquirir o que é necessário para tornar-se independente" (KANT, 1999, p.33).

$\mathrm{Na}$ obra de Paulo Freire, não percebemos a intenção de fazer um tratado sobre autonomia. Como bem destaca Streck (2003), até mesmo na Pedagogia da autonomia (Freire, 2008) são poucas as vezes que a palavra autonomia aparece citada diretamente. Porém, como conceito e categoria, ela está implícita em sua teoria, muitas vezes inerente a outros conceitos. Para Machado (2010), esta é uma categoria central na obra desse intelectual.

Paulo Freire não defende uma concepção idealista de autonomia. Para ele, não é apenas a consciência que a garante. "Ninguém é autônomo primeiro para depois decidir. A autonomia vai se construindo na experiência de várias, inúmeras decisões que vão sendo tomadas" (FREIRE, 2008, p.107).

A autonomia não é uma entidade abstrata que se desenvolve a partir de determinado conhecimento e que dá ao sujeito a capacidade de tomar decisões. Ela seria o resultado direto de uma relação entre conhecimento, consciência e ação, que se desenvolve no processo histórico (MACHADO, 2010). 
A categoria de autonomia não pode ser entendida descolada da teoria desenvolvida por Paulo Freire. Por isso, sua análise requer que voltemos a outros conceitos fundamentais trabalhados por ele. Começamos destacando o conceito de humanidade. O que é o homem na concepção freireana? O que o distingue de outros animais?

Ernani Maria Fiori, em sua leitura do pensamento Freire (2014a, p. 17), exposta no prefácio do livro Pedagogia do oprimido, relaciona a condição humana à palavra: "Com a palavra o homem se faz homem."

Todavia, percebemos claramente na obra de Freire que a condição humana se associa diretamente com a consciência do homem sobre a sua inconclusão e sua capacidade de agir no mundo produzindo cultura. Enquanto o animal é incapaz de separar-se de sua atividade, o ser humano tem tanto a sua intervenção no mundo quanto a si mesmo como objetos de sua consciência. Ele tem consciência de si e do que está em sua volta (FREIRE, 2014a).

Ao ter consciência de seu inacabamento, o ser humano toma ciência também do inacabamento do mundo. Diferente de outros animais, cria o seu mundo a partir da sua intervenção, produz cultura. Enquanto o mundo humano é histórico, uma realidade criada e produzido pelo homem, o mundo animal é a-histórico, "não se constitui em um eu para ele, que seja capaz de constituí-lo como eu" (FREIRE, 2014a, p.123).

Inerente ao sentido de humanidade em Paulo Freire está a capacidade de o homem intervir criando, recriando e transformando o seu mundo. Segundo ele, como o animal não se vê a parte do mundo, o mundo não se apresenta para ele como um contorno problemático. $O$ animal não é capaz de assumir reflexivamente os seus desafios. Sua condição a-histórica não lhe permite assumir a vida, que para ele se dá em um "suporte atemporal", em um plano igual. Já a existência humana é atrelada ao mundo humano, criado através da intervenção do próprio homem (FREIRE, 2014a).

A partir da ação humana, ou seja, no momento em que homens interviram no suporte e criaram o mundo, as contradições foram aparecendo, do tipo: "a decência e o despudor", a "boniteza e a feiura", etc. (FREIRE, 2008, p. 52).

Essa tensão de um ser inacabado consciente de seu inacabamento, $\mathrm{e}$ o mundo inacabado, coloca-o em relação de tensão direta com esse mundo. Isto exige do ser humano respostas e ações decisórias diante dos desafios.

É justamente a partir dessa concepção sobre inacabamento humano e a constante intervenção criadora do homem no mundo é que podemos entender o que Freire (2014a) chama de vocação do ser mais. O ser mais não é algo "inscrito" na história, porém é uma vocação histórica e por isso a sua negação é uma das negações do sentido de humanidade. 
Libertação e opressão não são realidades históricas inexoráveis, insuperáveis, inevitáveis. A opressão é desumanizante, uma vez que distorce a vocação humana de ser mais (FREIRE, 2014b, 130). A partir de então, temos mais duas proposições fundamentais na teoria freireana: sua concepção sobre a relação entre opressor e oprimido e a noção de condicionamento histórico.

A relação entre opressor e oprimido é compreendida como uma construção histórica, sendo assim, a simples negação da sua existência não implica a sua superação, mas a sua permanência. Conceber tal realidade como uma construção significa ater-se ao fato de que ela não é natural, ou seja, o mundo construído dentro do paradigma da dominação e da exploração não é o único possível. Da mesma forma que esse mundo foi construído historicamente, a sua superação só será possível no plano histórico, material. Não é um processo automático, um destino certo, mas uma possibilidade que se materializará apenas a partir da intervenção do próprio ser humano.

A dominação do homem sobre o próprio homem é desumanizante não apenas por subtrair aspectos de humanidade, mas por afetar a essência humana. É uma " distorção da vocação do ser mais". Mas essa distorção, como aponta Freire (2014a, p. 40), não é apenas uma possibilidade histórica, "mas não vocação histórica". A vocação do homem como ser inacabado é ser mais.

Afinal, não somos seres determinados historicamente. Esta é outra concepção fundamental em Paulo Freire, inclusive é o que dá a nós humanos a possibilidade de autonomia. Para ele a nossa passagem pelo mundo não é predeterminada ou pré-estabelecida. A história "de cuja feitura tomo parte é um tempo de possibilidades e não de determinismo", que faço não individualmente, mas na relação com os outros (FREIRE, 2008, p.53).

As relações de dominação não determinam a história, mas a condicionam. Por isso, o exercício de superação é possível. E a autonomia é uma construção coletiva; ou seja, ela se relaciona com o processo de emancipação. Enquanto este seria a superação das relações de opressão, aquela seria a tomada de consciência e ação dentro do processo de busca pela libertação.

Ao afirmar que a autonomia não precede a decisão, mas que esta se constrói nas diversas experiências em que decisões são tomadas, Freire (2008, p. 107) está afirmando que autonomia não é sinônimo de tomada de consciência. Mas que ela se constrói dialeticamente em uma relação histórica que envolve ação humana e consciência.

Em sua concepção, a consciência da opressão não basta para que haja superação da realidade. A consciência só é libertadora na medida em que se converte em ação de transformação. Não se trata de um ente abstrato que confere aos indivíduos a possibilidade de libertação, pelo contrário, é construída dialeticamente nas relações materiais. 
A partir de tais princípios, podemos pensar no que o autor entende por "ética universal".

Na verdade, falo da ética universal do ser humano da mesma forma que falo da vocação ontológica para o ser mais, como falo da natureza constituindo-se social e historicamente não como a priori da História. A natureza que a ontologia cuida se gesta socialmente na História.[...] Quer dizer, mais do que uma presença no mundo, o ser humano se tornou uma presença no mundo, com o mundo e com os outros. Presença que, reconhecendo a outra presença como não eu, se reconhece como "si própria". Presença que se pensa a si mesma, que se sabe presença, que intervém, que transforma, que fala do que faz, mas também do que sonha, que constata, compara, avalia, valora, que decide que rompe. Ee ne no domínio da decisão, da avaliação, da liberdade, da ruptura, da opção, que se instaura a necessidade da ética e se impõe responsabilidade. A ética se torna inevitável e sua transgressão possível é um desvalor (FREIRE, 2008,p.18).

A educação, em Freire, deve ser um projeto tanto ético quanto político. Ético porque se inscreve no papel de ser libertadora, neste caso contribuindo com o resgate do sentido de humanidade, de ser mais. Sendo assim, não pode ser bancária, depositária de conteúdo. Mas deve contribuir para o resgate da vocação ontológica de ser mais, rompendo com a lógica de dependência, possibilitando uma leitura crítica do mundo. E fazendo perceber que o mundo da dominação não é uma realidade natural e não é a única possível, mas uma construção histórica e que por isso pode ser superada. Nesse projeto de saber, agir e experienciar o mundo, o sujeito vai construindo a sua autonomia.

É um projeto político porque deve ser comprometida com um outro modelo de sociedade. Um modelo capaz de romper com a lógica de dominação. Por isso, o dominado precisa tirar o dominador de dentro de si. O que significa tirar de dentro de si a lógica da dominação, da subserviência cega, do apagamento de sua possibilidade de intervir, de ser mais.

A forma de efetivação prática desse projeto precisa ser construída a partir do respeito e do reconhecimento do outro. Por isso, a máxima de que os homens se educam em comunhão (FREIRE, 2014a).

O processo educativo deve se pautar no respeito ao outro, o que significa considerar o seu conhecimento do mundo. É o que Paulo Freire (2014b, p. 39, 98) chama de "saber de experiência feito". Porém, da mesma forma que a mera consciência da opressão não liberta o oprimido, a experiência do oprimido não pode ser um fim em si mesmo. Isso significa "partir do saber experiência feito para superá-lo". Uma das instrumentalidades dessa superação ocorre na defesa de um saber que considera a razão de 
ser das coisas, oposto ao simples depósito de conteúdo. Machado (2010, p.53) destaca que o processo de construção de autonomia em Freire é acompanhado por uma "reflexão crítica e prática".

A educação dentro dessa concepção deve estimular a curiosidade. Não uma "curiosidade domesticada", capaz de levar à simples memorização de conteúdos. Mas a curiosidade epistemológica, que fomenta a"capacidade crítica de tomar distância do objeto, de delimitá-lo, de cindi-lo, de cercar o objeto ou fazer sua aproximação metódica, sua capacidade de comparar, de perguntar" (FREIRE, 2008, p.85).

Educação e autonomia para Paulo Freire $(2008$, p.84) são realidades históricas; por isso, se concretizam por meio da característica humana de ser inacabado que intervém em um mundo que ele mesmo criou, por isso também inacabado. $O$ processo de libertação do dominado da figura do dominador se viabiliza no expurgo da sombra do opressor de dentro do oprimido."Sombra que, expulsa pelo oprimido, precisa ser substituída por sua autonomia e sua responsabilidade." Não é jamais um processo individualista, mas se realiza na ação na história e ganha sentido na coletividade.

A ação do indivíduo para Freire se constituiu em sua relação com o mundo, por isso, deve ser fundamentada na ética e na coletividade. A autonomia nasce daí. À medida que o indivíduo foge do projeto ético, foge da sua humanidade, uma vez que ética, para Freire (2008), não é uma propriedade idealista, mas nasce da vocação ontológica e histórica do homem se perceber como separado do outro e ao mesmo tempo reconhecer-se a si mesmo a partir dele. Por isso, a autonomia em Freire não é uma categoria individualista. Embora esteja relacionada à pessoalidade, é construída a partir da experiência do homem no mundo, mesmo porque, para ele, a pessoalidade só se faz possível a partir do reconhecimento do outro.

\section{EDUCAÇÃO, AUTONOMIA E CORROSÃO DO CARÁTER: ALGUMAS CONSIDERAÇÕES}

Tanto a Pedagogia da esperança (Freire, 2014b) quanto a Pedagogia da autonomia (Freire, 2008) foram escritas por Paulo Freire no Brasil, na década de 1990, mais especificamente em 1992 e 1996 respectivamente, sendo a última um ano antes de sua morte. Tempos em que o neoliberalismo se consolidava no país e sua lógica já percorria o mundo, ou pelo menos grande parte dele.

Em ambos os livros, ele não se furtou em criticar e confrontar este que é mais que um modelo econômico, é uma lógica de vida e de organização social: "Daí a crítica permanentemente presente em mim à malvadez neoliberal, ao cinismo de sua ideologia fatalista e a sua recusa inflexível ao sonho e a utopia" (FREIRE, 2008, p.14). 
Considerando as críticas feitas ao homem contemporâneo, "autônomo", individualista, instrumental, Streck (2003) e Machado (2010) apontam que Freire (2008) surpreendeu ao discutir sistematicamente o conceito de autonomia. Não foi por acaso que Freire se posicionou logo nas primeiras páginas da Pedagogia da autonomia, mostrando de onde falava.

A sociedade contemporânea, fundamentada na lógica do capitalismo flexível e consequentemente caracterizada pelo que Sennett (2014) bem denominou de corrosão do caráter, acentua o princípio da exploração e administra com êxito um projeto de desumanização, ao levar a instâncias cada vez mais altas a máxima capitalista de coisificar homens e mulheres, transformando-os em mercadoria, ao metamorfosear as relações humanas em relações meramente comerciais. Isso ao tirar dos sujeitos a possibilidade de construírem narrativas significativas e, finalmente, tentar apagar uma das mais belas e humanas das características, a possibilidade de autoria.

A proposta freireana de autonomia, ancorada em outros aspectos de sua teoria, apresenta contrapontos importantes, que nos ajudam a pensar um modelo de educação comprometido com outra possibilidade de mundo. Enquanto o modelo de sociedade em curso é totalmente desumano e desumanizante, a teoria freireana se compromete com uma proposta de resgate do sentido de humanidade. Conforme destaca Machado (2010, p. 53), "autonomia é um processo de decisão e humanização que vamos construindo historicamente".

A tendência de menosprezar e negar narrativas significativas, de romper com o sentido de trajetória, de carreira, como destacadas por Sennett (2014), coloca o sujeito contemporâneo em uma profunda crise de identidade. Isto porque, além de ofuscar sua historicidade, sua capacidade humana de criar, de interferir, confina-o também em uma situação de isolamento, de solidão, oriunda da lógica individualista. Hobsbawm (2008), foi bem preciso ao chamar a sociedade do pós-década de 1970 de uma sociedade que perdeu as referências.

Entretanto, ao trazer a categoria de autonomia a partir de Paulo Freire, como uma possível resposta a este tempo, não o fazemos no sentido de resgatá-la como referência ao modelo do capitalismo na etapa do Estado de bem-estar social. Mesmo porque entendemos que a proposta capitalista é desumanizante por si só. Nesse sentido, as referências que buscamos de volta são aquelas que nos identificam como seres humanos.

O conceito de autonomia em Freire tem o mérito de ser extremamente humanizante, assim como é sua teoria como um todo. Ao reconhecer o homem como produtor de história, vocacionado a ser mais, a intervir sempre 
em uma realidade, que não é natural, mas criada por seres humanos e, consequentemente, exterior aos homens, recuperamos o sentido de autoria. E é nesta relação de autoria com o mundo que o homem toma decisões e constrói a sua autonomia, a partir de uma trajetória consciente e crítica.

Quando reconhecemos que o mundo, por ser uma invenção humana, é também inacabado, como o é seu criador, abrimo-nos para a possibilidade de ir além, de reinventarmos. Como destaca o próprio Freire (2014b), reconhecer não basta, afinal o mundo não é mudado pelo sonho e pela esperança de que ele pode ser melhor, mas a partir da intervenção histórica do homem na realidade.

A partir dessa perspectiva, temos uma espécie de concepção antropológica de Freire. Ela é ancorada na noção de inacabamento do homem, vocacionado a ser mais, e que se reconhece como humano na relação com outros homens e que, por isso, tem de respeitá-los em sua criatividade e seu inacabamento, uma vez que a negação do outro, neste sentido, acaba sendo a negação de si mesmo. Tal perspectiva se contrapõe totalmente ao individualismo.

Por ser ético, o sentido de autonomia em Paulo Freire é totalmente democrático. Não nos referimos à democracia aqui no sentido esvaziado do termo, atrelada à mera possibilidade de votar nos governantes, por isso usada, na maioria dos casos, para legitimar e sustentar a ordem vigente e suas injustiças. Mas sim da "democracia como valor universal" (Coutinho, 1979). 0 que significa uma garantia efetiva de participação na vida social e econômica, não comprometida com a legitimação de nenhum tipo de estrutura injusta ou dominação. Democracia no sentido de participação das massas, não apenas figurativamente, mas em um processo de divisão do poder e como ponto de partida e de chegada de uma sociedade igualitária, sem divisão de classes.

Igualdade democrática em Freire (2014b) não se constitui na negação das diferenças, mas em uma dialética entre diferença e igualdade. As diferenças não são necessariamente motivo de subjugação, de negação de humanidade. Machado (2010, p. 53) refere-se à concepção freireana de autonomia como parte da "construção de uma sociedade democrática que a todos respeita e dignifica".

Autonomia é um processo educativo, não apenas no sentido escolar do termo, na medida em que se desenvolve na trajetória, nas experiências do sujeito no mundo. Sendo um processo educativo, não é imparcial. A neutralidade, tão propagada na sociedade neoliberal, é duramente criticada por Paulo Freire. É uma forma de negar a possibilidade de crítica, de superação. 
"Qualquer que seja a prática educativa, autoritária ou democrática, ela é sempre diretiva" (FREIRE, 2014b).

Sendo assim, a opção por uma educação democrática não pode se estruturar na lógica de transferência de conteúdo. Deve respeitar a autonomia de professores e alunos. E, embora respeite o senso comum, deve ser capaz de superá-lo, deve transitar da curiosidade ingênua à curiosidade epistemológica, afinal é neste ponto que a autonomia na prática educativa se constrói e amadurece.

Em tempos de corrosão do caráter, Freire nos desafia a reassumirmos nossa vocação de autoria, pois a história é uma possibilidade. Na dialética entre pessoalidade e coletividade, fazemo-nos humanos. Afinal, nos reconhecemos no reconhecimento do outro.

\section{AUTONOMY INTIMES OF FLEXIBLE CAPITALISM: AN APPROACH FROM PAULO FREIRE}

ABSTRACT: The article reflects on the category autonomy in Paulo Freire, its relevance and applicability in the current stage of capitalist society. It is a theoretical approach that in the first moment discusses the concept of character corrosion (SENNET, 2014) in the context of flexible capitalism. Then, it presents the concept of autonomy in Freire $(2008,2014 a$ and 2014b) based on other postulates of his theory. At the end, it indicates counterpoints between the logic of the society of flexible capitalism, the corrosion of character and the Freirean conception of autonomy. Among the results, the autonomy in Freire as a humanizing proposal stands out, which rescues the sense of authorship and opposes the inhumane process that governs the current capitalist society.

KEYWORDS: Autonomy. Authorship. Character corrosion. Incompleteness.

\section{AUTONOMÍA ENTIEMPOS DE CAPITALISMO FLEXIBLE: UNA APROXIMACIÓN DESDE PAULO FREIRE}

RESUmEn: En este artículo se reflexiona sobre la categoría de autonomía en Paulo Freire, su relevancia y aplicabilidad en la etapa actual de la sociedad capitalista. Se trata de un enfoque teórico que, inicialmente, analiza el concepto de corrosión del carácter (SENNET, 2014), en el contexto del capitalismo flexible. A continuación, introduce el concepto de autonomía de Freire (2008, 2014a y 2014b) sobre la base 
de otros postulados de su teoría. Al final se presentan contrapuntos entre la lógica de la sociedad del capitalismo flexible, la corrosión del carácter y la concepción de autonomía en Freire. Entre los resultados se destaca la autonomía en Freire como una propuesta de humanización que rescata el sentido de la autoría y se contrapone al proceso inhumano que rige la sociedad capitalista actual.

Palabras-Clave: Autonomía. Autoría. Corrosión del carácter. Inacabamiento.

\section{REFERÊNCIAS}

COUTINHO, Carlos Nelson. A democracia como valor universal. Rio de Janeiro: Civilização Brasileira, v. 9, p. 33-47, 1979. Disponível em: <http://pt.scribd.com/doc/49636615/A-Democracia-como-Valor-Universal>. Acesso em: mar. 2014.

FREIRE, Paulo. Pedagogia da autonomia: saberes necessários à prática educativa. São Paulo: Paz e Terra, 2008.

. Pedagogia do oprimido. 58.ed. Rio de Janeiro: Paz e Terra, 2014a.

.Pedagogia da esperança: Um reencontro com a pedagogia do oprimido. 21.ed. São Paulo: Paz e Terra, 2014b.

FRIEDMAN, Milton. Capitalismo e liberdade. 3. ed. São Paulo: Nova Cultural, 1988.

HAYEK, Friedrich August von. O caminho da servidão. 5. Ed. Rio de Janeiro: Instituto Liberal, 1990.

HOBSBAWM, Eric. Era dos extremos: o breve século XX: 1914 - 1991.São Paulo: Companhia das Letras, 2008.

KANT, Immanuel. Sobre a pedagogia. Piracicaba: Editora Unimep, 1999.

. Fundamentação da metafísica dos costumes. Lisboa: Edições 70, 2007.

MACHADO, Rita de Cássia de Fraga. Autonomia. STRECK, Danilo R.; REDIN, Euclides; ZITKOSKI, Jaime José (Org.). Dicionário Paulo Freire. Belo Horizonte: Autêntica, 2010, p. 53-54.

STRECK, Danilo R. Educação para um novo contrato social. Petrópolis: Vozes, 2003.

SENNETT, Richard. A corrosão do caráter: consequências pessoais do trabalho no novo capitalismo. 18. ed. Rio de Janeiro: Record, 2014.

. A cultura do novo capitalismo. Rio de Janeiro: Record, 2006.

ZATTI, Vicente. A educação para autonomia em Immanuel Kant e Paulo Freire. 2007. 100f. Dissertação (Mestrado em Educação) - Universidade Federal do Rio Grande do Sul, Porto Alegre, 2007. 
ANDERSON JOSÉ LISBOA BAPTISTA é doutorando e mestre em Educação pela Universidade Federal Fluminense (UFF). É especialista em Educação de Jovens e Adultos e graduado em História pela Universidade Estácio de Sá.

E-mail: andersonbaptista@yahoo.com.br 